\title{
EL ODIO AL DESEMPLEADO: GENEALOGÍA CRÍTICA Y ANÁLISIS PRAGMÁTICO DE SUS MANIFESTACIONES DISCURSIVAS
}

\section{HATRED OF UNEMPLOYED: CRITICAL GENEALOGY AND PRAGMATIC ANALYSIS OF ITS DISCURSIVE APPEARANCES}

\author{
Miguel Rosso Carrasco \\ Universidad de Cádiz, UCA, Cádiz, Espanha \\ Daniel López Romero \\ Universidad Pablo de Olavide, UPO, Sevilla, Espanha
}

\begin{abstract}
Resumen: realizándose un análisis filosófico al respecto del desempleo como reverso nunca cuestionado del imperativo categórico del trabajar, propio de la cultura occidental, se aborda la problemática en torno al fin del trabajo que nos hace vislumbrar la sociedad posindustrial. Esto lleva a constatar fuentes documentales que atestigüen la presencia de discursos de odio, más o menos sutiles, hacia el desempleado. Por último, se aborda la cuestión de cómo analizar teóricamente, desde la pragmática, la dimensión normativa del discurso de odio hacia el desempleado.
\end{abstract}

Palabras clave: ética del trabajo, desempleo, discurso de odio, actos de habla, normatividad.

Abstract: Unemployment is analyzed from a philosophical approach, as a never questioned side of the categorical imperative of working in western societies. Problems towards the end of work arisen by the postindustrial era are tackled in this part. Subsequently, documentary research is carried out to detect the presence of hate speeches, more or less subtle, about unemployed. Lastly, we deal with the problem about how to analyze, from pragmatics theory, the normative dimension of hate speech about unemployed.

Keywords: work ethic, unemployment, hate speech, speech act, and normativity.

\section{Introducción: presentación de contenidosy disquisiciones metodológicas}

Dentro del panorama actual del análisis crítico de los discursos intimidatorios, se encuentran de forma relativamente frecuente trabajos sobre discursos de odio por razones étnicas, de género, religiosas, etc., pero lo cierto es que raramente se formula la pregunta al respecto de si el colectivo de los desempleados en las sociedades occidentales podría ser objeto de discursos de odio. Queda plenamente justificado, pues, el interés investigador concerniente a valorar si puede contemplarse ese colectivo 
como objeto de dicho discurso y, si es así, qué enfoque pragmático debería seguirse: si acaso el mismo que para otros colectivos o si, por el contrario, goza de ciertas particularidades que aconsejan otras aproximaciones. Este carácter tentativo del artículo lo marca metodológicamente, pues, de entrada, su alcance, lejos de ser una mera presentación de resultados, como se estila en revistas científicas, es una reflexión metodológica de carácter filosófico al respecto de: 1) si se puede conformar un nuevo objeto de estudio y 2) de qué forma podría estudiarse. La argumentación en torno a estos dos puntos se condensa en el apartado de conclusiones.

En cuanto al planteamiento de la utilización de corpus, se razona en el apartado 3 del presente artículo, aunque se adelanta aquí, que, puesto que la fuente última de la muestra discursiva de odio no reside en características léxicas o discursivas reflejables en el código lingüístico, al menos de forma preponderante, basarse en corpus es solo limitarse a la superficie del fenómeno: se precisan teorías que no se queden solo en "lo que se dice", sino también en "lo que se implica", y es donde entran en juego la valoración de diversas teorías pragmáticas para atender estos fenómenos.

El método utilizado es, en los apartados 1 y 2, una aproximación filosófica concebida como una ontología del presente desde una óptica foucaultiana, acompañada en el apartado 3 y posteriores por una clarificación de carácter metapragmático para valorar racionalmente qué teorías pragmáticas pueden dar cuenta de las manifestaciones discursivas e intencionales, no solo estrictamente lingüísticas, de los discursos de odio hacia los desempleados.

Terminológicamente, si bien se desgrana con mayor detenimiento ciertos matices e implicaciones conceptuales al final del punto $2 \mathrm{y}$ en el punto 3 , se usarán indistintamente los términos similares, aunque no iguales ni en contenido conceptual ni en carga connotativa, "discurso de odio" y "discurso intimidatorio", empleándose generalmente el primero por su mayor uso en la literatura actual.

En cuanto a la estructura del artículo, se analizará: 1) En su primera parte, el trasfondo social, cultural e ideológico con el que las sociedades occidentales abordan la esfera del trabajo, planteando tanto un impensado imperativo del trabajar, la pérdida identitaria que supone subsumir al ser humano en trabajador y la transformación cultural que implica iniciar una época posindustrial en el que el trabajo mismo queda en suspenso; 2) en la segunda parte, se expondrán diversos ámbitos en los que se reflejan algunas de estas características en determinados discursos; 3) por último, el artículo concluye analizando con qué herramientas pragmáticas puede abarcarse el 
discurso de odio hacia el desempleado, especialmente pensando en último término en cómo podrían reflejarse su dimensión normativa (es decir, no solo en lo que el enunciado dice ni en lo que quiere decir, sino también en lo que debe decir).

\title{
1. Situación del desempleado en el contexto del fin de la sociedad del trabajo
}

\author{
"El concepto de "parado" no remite entonces, en última instancia, a \\ ninguna realidad tangible y aislable; expresa únicamente la obligación \\ de trabajar, y el hecho de que esta obligación se ejerce, en la sociedad \\ mercantil, a nivel individual. La inocente maniobra con la que una falta \\ de cualidad se transforma en cualidad particular y la no-pertenencia a \\ una categoría en una categoría distinta, no tiene nada de neutro; dicha \\ maniobra es lo que funda todo el exorbitante poder de constreñimiento del \\ mundo de la mercancía autoritaria" (TIQQUN, 1999).
}

\section{1 Ética del trabajo y desempleo}

Pleno de sesiones del Congreso de los Diputados español, el 11 de julio de 2012. Este en el marco en el que la diputada popular Andrea Fabra profería un aparentemente cínico y desenfadado "que se jodan" a los comentarios de la oposición socialista al anuncio de nuevos recortes en la prestación por desempleo por parte del Gobierno del Partido Popular. Este comentario provocó una ola de indignación generalizada, que pareció conmover la opinión pública. Resultaba inconcebible que se pudiera superar tan a las claras, no ya el límite del decoro y la exigida ejemplaridad parlamentaria, sino el mínimo compromiso de sensibilidad con el eslabón más débil de la crisis económica: el de aquellos golpeados con el azote del desempleo.

Tras la pública disculpa de la diputada, y más allá de toda la suspicacia legítima de los grupos de opinión o de la rentabilidad que pudo sacar la oposición de este "desliz" para su propio argumentario, quedó restablecido algo que, a nuestro juicio, remite a un consenso fundamental de gran calado en el que nos gustaría detenernos.

Nos referimos, en primer lugar, a la debida preocupación por el "colectivo de desempleados" Pero, de un modo más fundamental y, al margen de la efectiva erosión del contenido del artículo 41 de nuestra carta 
magna ${ }^{1}$ que las políticas laborales recientes pudieran estar provocando, con esta disculpa ${ }^{2}$ parecía quedar restaurada la convergencia del sentido común general de todas las fuerzas políticas en la incuestionabilidad del art. 35 .

Es decir, de aquel que establece que todos los españoles tenemos reconocidos de manera indisoluble, en la base de nuestro ordenamiento jurídico, el deber de trabajar y el derecho al trabajo. Que, por tanto, el desempleo ha de entenderse siempre, prima facie, como una lamentable disfunción o accidente que no entorpece la firmeza de un hecho sustancial, cual es el de la compulsión (FREUD, 1927) (BENJAMIN, 1921) hacia el trabajo como una suerte de ethos común ${ }^{3}$, como la base fundamental de nuestra cohesión social y, si no la única, posiblemente como la garantía jurídica fundamental de la supervivencia material de la población.

Asumido esto, casi no hay imperativo más inatacable que aquel que la propia Andrea Fabra aprovechó para esgrimir en su escrito de disculpa, esto es, el que apelaba a la necesidad de volver, cuanto antes y por encima de cualquier otra consideración, a la senda del crecimiento y de la creación de empleo.

En perfecta coherencia con esto, tampoco es casual que fuera la eventual "degeneración" de este dispositivo jurídico el motivo impulsor de la decisión gubernamental de reformar las prestaciones. La polémica reforma venía justificada por el peligro de una eventual desincentivación en el cumplimiento de este deber jurídico esencial. El desempleado tiene, pues, en este escenario, que hacer frente a su situación con la asistencia de los poderes públicos, pero sin que, en ningún momento, la provisional interrupción de su derecho y/o la percepción de un determinado ingreso pueda interferir un ápice el cumplimiento de su deber. $\mathrm{O}$, dicho lisa y llanamente, los ciudadanos españoles, desempleados o no, tienen en todo momento la perentoria obligación de trabajar y, en consecuencia, es a ella a la que deben alentar las medidas públicas de forma prioritaria.

Nada más indeseable, podemos colegir entonces, que una proliferante desafección hacia el mundo del trabajo penetrando en el conjunto de la población española. Como si esto que estamos denominando, todavía

${ }^{1}$ Art 41.los poderes públicos mantendrán un régimen público de seguridad social para todos los ciudadanos que garantice la asistencia y prestaciones sociales suficientes en caso de necesidad, especialmente en caso de desempleo" erosión que habría de producirse a todas luces con la implementación de la medida que motivara el exabrupto

${ }^{2}$ Insistimos, por muy simulada u obligada que se juzgara su disculpa y rectificación.

3 "Ethos común" con el sentido concreto de valores compartidos o consensos tácitos dentro de una comunidad política, término recurrente en la reflexión política contemporánea vinculada al paradigma biopolítico (cf. BAZZICALUPO, 2016). 
vagamente, como "sociedad o mundo del trabajo" se sostuviera, de veras, solo sobre dicho tejido de netas obligaciones comunes, sobre una mera ética del trabajo, por más metafísicamente enraizada que se la presuma, al margen de su efectivo cumplimiento o de sus verdaderas posibilidades de materialización. Que es, por tanto, lamentable padecer en torno a un veinte por ciento de tasa de desempleo (EPA, 2012-2016), pero sería de todo punto inasumible una bolsa permanente de población disuadida de la necesidad de trabajar.

Que, en definitiva, el verdadero peligro límite a evitar, en este terreno, no es precisamente la pérdida del trabajo, o, tan siquiera, la depauperización que le sigue como su inmediata consecuencia, sino algo aún peor: la transfiguración que podría sobrevenir al agente sujeto a dicha obligación constitucional, desde el momento en que fuera capaz de desocupar su espacio social y articular una fórmula de un tenor parecido a este "No, ni trabajo ni estoy desempleado, lo que sucede es que no quiero trabajar"

Una suerte de cinismo anarquizante, subversivo y casi irrepresentable para ese consenso restaurado al que hacíamos referencia. Lo que revolvió de indignación a las oyentes de la declaración primera de Andrea Fabra fue, con toda seguridad, la falta absoluta de solidaridad con ese colectivo privado de su derecho al trabajo, pero a quienes, no obstante, nuestro sentido común presume siempre- amén de asolados por la necesidad- pertinazmente imbuidos del deber de trabajar.

En nuestro más reciente debate público, por más crítico que se presente, nadie parece plantear la más leve sombra de duda sobre este particular (como excepciones, cabe mencionar la presencia que están alcanzando las propuestas de renta básica en la agenda de algunos partidos políticos, de la mano de reputados valedores teóricos como el economista Raventós (2005), concebida dicha renta como la implementación de salarios de ciudadanía social frente a la imparable desregulación del mercado laboral)

A pesar, pues, de la precarización progresiva de lo que otrora fue el trabajo con derechos (LACALLE, 2009) el desempleado, que es algo así como su límite degradante extremo: la "zona cero" de ese trabajador desposeído de su andamiaje jurídico hasta la pérdida del último de sus derechos, que es el derecho al trabajo en sí mismo, seguiría siendo, en cambio, en términos de obligaciones como miembro de una institución social, un trabajador más.

El trasunto ético del mandato constitucional, por tanto, parece situar el modelo de dignidad humana en la búsqueda incesante de un bien escaso. Antes que, por ejemplo, en el rechazo y abandono positivo del mal de la propia escasez que es su medio. (SARTRE, 2004) 
¿Pero qué ocurriría si esa sociedad del trabajo se hallara en franca descomposición desde hace casi cuarenta años sin remisión posible (OFFE, 1984)? ¿Sería verdaderamente tan de temer este cinismo renuente a la constricción laboral o estaríamos ante un ejercicio de profanación (AGAMBEN, 2005) tan necesaria como urgente? De hecho las lógicas de la competitividad global, la progresiva descentralización empresarial y la flexibilidad laboral, que caracterizan el escenario postfordista hoy hegemónico en la economía internacional, han ya de suyo erosionado esa presunta compacidad del trabajador compulsivo que venimos analizando (BOLTANSKI; CHAPIELLO, 2002). En este escenario, las medidas contra el desencanto ante el trabajo que implementara el gobierno de Rajoy (y que se cifraban básicamente en un recorte progresivo de la prestación por desempleo durante el periodo en el que se es beneficiario) se vuelven directamente lesivas de la ya irremisiblemente erosionada figura del trabajador tradicional. Es la propia realidad del mercado de trabajo la que primero ha operado un proceso de descomposición y desarticulación imparable arrastrando tras de sí a la propia figura del trabajador. Y es esta relación entre el trabajador y su contexto de libre concurrencia, el mercado de trabajo, una relación de co-determinación estrictamente dialéctica solo ideológicamente separable (LAHIRE et al., 2005) Ante una realidad de incesante cambio es pernicioso seguir consagrando la fijeza e integridad de una subjetividad que, por más que sancionada constitucionalmente, parece condenada a un perpetuo desajuste.

Por otra parte, estamos asistiendo a un emergente fenómeno de internalización de la forma empresa, denominado emprendedor, tan abrumadoramente alentado hoy desde los poderes públicos, que invita a sospechar su valor estratégico como respuesta vehemente a esta problemática. Basta observar el carácter transversal a las políticas gubernamentales de esta autodenominada "cultura emprededora", para certificar su intención hegemónica. El horizonte productivo que estas políticas vislumbran es el de una sociedad de emprendedores o individuos empresa como respuesta más efectiva a las exigentes y frenéticamente cambiantes demandas del mercado de trabajo.

De modo que, junto al dogma de la compulsión hacia el trabajo y casi el tabú sobre el que sería poco menos que su reverso tenebroso: el rechazo del mismo (posición, en cambio, bastante en boga hoy, por ejemplo, entre determinadas formas de anarquismo postizquierdista, (BLACK, 2013) en el ámbito anglosajón o el propio colectivo anónimo Tiqqun) estaríamos asistiendo a la siembra, minuciosamente orquestada desde nuestras instituciones, de la nueva cultura del trabajo por venir, la que 
habría de generar una sociedad de individuos llamados a una maximización integral del recurso que es su propia vida entendida como capital rentable (MORUNO, 2015)

¿En qué lugar quedaría entonces el desempleado? Si de veras, en este nuevo relato del secular conflicto capital-trabajo, la empresa pasa a convertirse en el deber ser de los propios sujetos, podríamos aventurar, acaso sin mucho desacierto, que el desempleado sencillamente ya no tiene cabida alguna. $\mathrm{O}$ dicho de otra manera, que no tiene más cabida, ahora sin ningún tipo de ambages, que la del parásito del sistema y acaso hasta enemigo del bien común.

Si la solución que finalmente prospera tras el diagnóstico del fin de la sociedad del trabajo, en el que a continuación nos detendremos con más detalle, es la basada prioritariamente en el imperativo del autoempleo como remozado nuevo ethos común, el desempleado sería devuelto casi a un prisma de economía clásica, que, como es sabido, sostenía la práctica inexistencia de un desempleo involuntario, tesis basada, obviamente, en el postulado de la nula rigidez salarial. Existen de hecho estudios, ya de cierta antigüedad y también de inequívoco sesgo ideológico, que de hecho defienden el encaje del modelo del mercado de trabajo espańol en teorías de este corte neoclásico, como el modelo insider-outsider (FERREIRO, 2004).

El único desempleo concebible sería, en este escenario, el sobrevenido al sujeto que se desmarque de esta nueva relación entre trabajo y vida, sobre el que no podría más que recaer toda la semántica del fracasado, del loser. Toda vez que se ha borrado la frontera entre vida y trabajo, aquel que no trabaja es aquel que, valga la expresión, se auto-desemplea, es decir, aquel que desprestigia lo más valioso que se tiene, la marca que es tu propio yo (SAVATER, 2015)

¿Será entonces esto, como decíamos, la respuesta que determinadas políticas neoliberales de gobierno están presentando ya a la desaparición del viejo sueño de la plena ocupación, a la insoluble asimetría subrayada aquí entre el moribundo derecho al trabajo y el inamovible deber de trabajar? ¿Podría esta glorificación del emprendedor erosionar más si cabe el estatuto ya difuso del desempleado, delimitado aquí como una mera realidad negativa, como poco más que un trabajador temporalmente sin atributos, nada más allá de su obligación de "volver a trabajar"? según rezaba la cita de Tiqqun con la que abríamos esta reflexión- ¿Y cabría rastrear, en dicha intensificación sin precedentes de su vulnerabilidad, la posible emergencia de discursos de odio asociados a su figura y a su percepción social? Será lo que nos corresponderá explorar a continuación. 


\section{2 "Fin del trabajo"}

Si seguimos a Enrique de la Garza Toledo (1999), debemos apreciar cómo las diferentes teorías sobre el fin del trabajo desarrolladas en el último tercio del siglo veinte, tienen todas como común denominador un exceso de construcción y totalización teórica y considerablemente menos de refrendo empírico. Por tanto, no se trata ahora de asumirlas al pie de la letra sino de valorar los diferentes perfiles que brindan en torno a las decisivas transformaciones sociales acaecidas y todavía en curso.

Según de la Garza, en realidad pueden reagruparse en torno a cuatro tesis principales que no estaría de más recordar:

(1) Fin del trabajo entendido como consecuencia de la crisis del modelo industrial y la creciente heterogeneidad de los trabajadores con influencia en sus normas, valores y actitudes.

(2) Fin del trabajo como fin de la centralidad del trabajo en el conjunto de las relaciones sociales.

(3) Como progresiva extinción de su función generadora de valor.

(4) Fin del trabajo como derrota definitiva de la clase obrera acaecida en los ochenta, con los cambios en el régimen de acumulación y la crisis sindical.

Tesis todas afectadas de la subrayada tentativa de totalización y de cierto exceso de futurología. Para de la Garza cabe, no obstante, un planteamiento menos tremendista de este diagnóstico del fin y más atinente a efectivas constataciones empíricas. Hablar del fin significa primariamente, entonces, constatar que lo que se produce en los países que han gozado de cierta impronta del modelo de Estado bienestarista, es una reducción drástica del trabajo formal, estable y su sustitución por otras formas de trabajo consideradas anomalías, sin duda, en los países desarrollados, pero muy normalizados en economías del subdesarrollo. Desconocer esto es además un déficit de las propias ciencias sociales, deudoras largo tiempo del modelo de trabajo industrial: asalariado, organizado, regulado y protegido.

El trabajo propiamente no termina con el advenimiento del neoliberalismo lo que hace es fragmentarse, volverse discontinuo y al mismo tiempo alterar otras esferas otrora nítidamente separadas de la producción (indistinción grosera entre vida y trabajo que subrayamos en el punto anterior 
a propósito de la figura del emprendedor) La solución que de la Garza va a brindar a la problemática del "nuevo sujeto" que esta nueva configuración de las relaciones labores plantea es, no obstante, relativamente optimista. Se trataría de asumir el carácter dinámico de estas nuevas subjetividades sin aspirar a otra nueva hegemonía. Apostar por la convergencia de identidades múltiples en una coexistencia social no vertebrada ya en torno a la centralidad del trabajo y que, con todo, asumen la mutua contaminación entre los tiempos de producción y reproducción social.

Quizás el punto más significativo de esta última tesis para nuestros intereses aquí, se sitúa en esa idea de las identidades complejas, diversas y sustraídas a toda hegemonía identitaria. En el caso de la figura que nos ocupa, los desempleados, dicha sugerencia resulta crucial si tratamos de pensar en un estatuto para este colectivo que de veras le brinde no ya el sostén sino la identidad y verdadera capacidad de agencia social que siempre se le ha sustraído. Asumir el desempleo como una experiencia biográfica junto a otras, dentro lo que denomina de la Garza biografía laboral-reproductiva (1999, p. 18), puede al menos provocar una integración menos ideológica entre trabajo y desempleo, específicamente, permite abandonar la estrecha concepción del último como fase de neta recapitalización de recursos para la vuelta a la empleabilidad, por no hablar de la estigmatización de su figura que queremos visibilizar aquí.

\section{3 ¿Existe un discurso de odio hacia los desempleados?}

Existe como poco una economía política de las emociones, por usar la expresión de la investigadora Sara Ahmed (2004). Considerar que la emoción tiene primariamente una génesis psicológica es inexacto, como lo era confiar en la inexistencia del desempleo involuntario. La emoción, lo que uno siente, como lo que uno piensa tiene, por tanto, una raíz social y colectiva. Las emociones, además, delimitan espacios y abren distancias, permiten separar un nosotros de un afuera en un mismo dispositivo emocional públicamente compartido, inscrito en los cuerpos y en sus agrupamientos colectivos, así como en sus exclusiones y desagregaciones. Por tanto, según la investigadora británica la emoción genera y legitima desigualdades. Estos códigos emocionales transitan en los textos y discursos públicos generando simultáneos efectos de desafección y de contagio emocional. En línea con este análisis de Ahmed, cabría rastrear al hilo de determinadas manifestaciones de discursos de odio hacia el desempleado que serán analizadas en la segunda parte de este trabajo, la efectiva estructura 
que permite la reproducción social de determinadas emociones y no de otras. Por ejemplo, de la que hace posible que nos sintamos más culpables que víctimas ante el desempleo y que inequívocamente se destila de muchas de las estrategias implementadas por servicios públicos de orientación al empleo (ver $2^{\mathrm{a}}$ parte).

Las estructuras atravesadas de códigos emocionales sobre las que en definitiva descansan y sostienen su éxito culturas emergentes, como la nueva cultura del emprendedor o estrictas patologías sociales como el miedo al desempleo. La idea de defenderse, pues, frente a la proliferación de determinados discursos de odio, más allá de su visibilización y limitación penal, habría de ir, en consecuencia, especialmente en el caso un tanto escurridizo que nos toca, el de la percepción social del desempleo, en la línea de una reeducación emocional de los agentes implicados a través de una efectiva recodificación emocional de determinados acontecimientos regulares en el mundo laboral como son su búsqueda, su perdida y cómo no, la eventual decisión de descentralizar el papel del trabajo dentro de nuestros proyectos sin carga emocional. Neutralizar el miedo, la culpa y la vergüenza como dispositivos legitimadores del estatus quo. Tres emociones legitimadoras de la desigualdad en el análisis de Ahmed y que son inequívocamente la triada emocional que atenaza al colectivo de los desempleados ¿¿Acaso resultado de la movilización, si no del odio, sí al menos del rechazo social a su situación? Se trata de una vía que se revela bastante promisoria para eventuales análisis futuros en convergencia con el fenómeno del discurso de odio al desempleado que nos ocupa. odio?

¿Qué convierte a una manifestación determinada en un discurso de

De modo provisional, acaso puede valernos la definición brindada por Kaufman (2015, p. 48):

Una opinión dogmática, injustificada y destructiva respecto a ciertos grupos históricamente discriminados o a ciertas personas en tanto integrantes de dichos grupos, emitida con el propósito de humillar y/o transmitir tal dogma destructivo al interlocutor o lector y de hacerlo partícipe de la tarea de marginalizar o de excluir a las personas odiadas.

El objeto del análisis que antecede ha sido fundamentalmente el intentar hacer sensible a la comprensión del auditorio, la posible adecuación a esta matriz de determinadas piezas de discurso en torno a los desempleados que pugnan por hacerse hegemónicas. Suscitar al menos la pregunta por la 
eventual emergencia de dicho discurso de odio, cuya respuesta habrá de ser tratada detalladamente en la segunda parte.

\section{Constatación del fenómeno: presentación y clasificación no exhaustiva de casos de enunciados intimidatorios}

Una vez que se ha confirmado que el colectivo de los desempleados en las sociedades occidentales parece un candidato claro para ser objeto de determinados discursos intimidatorios, resta aún por comprobar en qué grado se cumple esto, qué repercusión fáctica tiene en las redes sociales y, sobre todo, qué recursos nos brindan algunas de las disciplinas lingüísticas para detectar rasgos inequívocos de esos discursos. Dentro de estas disciplinas lingüísticas, nos serviremos especialmente de la pragmática. Creemos que dicha disciplina consigue superar un inconveniente frecuente cuando se intentan constituir corpus al respecto. Como demuestran ciertos estudios (por ejemplo, RAZAVI et. al., 2010), el intento de detectar automáticamente discursos de odio basándose en palabras clave solo lleva a tasas de éxito inferiores al $40 \%$. Esto mismo puede comprobarse si acudimos a corpus especializados en español, como el Corpus del Español de la $B Y U$ o el CREA de la RAE, donde la búsqueda de palabras clave en contexto consigue resultados muy poco significativos e incluso irrelevantes. Aunque ciertamente este porcentaje puede mejorarse mediante métodos de validación cruzados, una de las dificultades más palpables es que realmente la fuente última de la muestra de odio no reside en características léxicas o discursivas reflejables en el código lingüístico, sino en la intención del emisor a la hora de emitir ese mensaje. Ciertamente con ello no se quiere sostener que la intención sea una condición necesaria para causar ofensa, como también defiende Culpeper (2011, p. 52), pero sí que hay una relación probable entre intención de ofender y discursos de odio ${ }^{4}$. Si

\footnotetext{
${ }^{4}$ Podría plantearse como hipótesis que esta cuestión es aún más palpable en lo que respecta al discurso de odio dirigido al desempleado —o incluso a la noción misma de desempleo, como puede sostenerse a partir de nuestra primera parte-, por ser una discriminación más sutil y que no cuenta con un reconocimiento histórico equiparable a la discriminación a otros colectivos como en función de etnia, género, ideología, etc. Por ejemplo, en la Declaración universal de Derechos Humanos, en su artículo 2, no se hace ninguna mención expresa al desempleo, siendo lo más cercano la "posición económica". Igualmente, en los recursos online de la Oficina del Alto Comisionado de las Naciones Unidas para los Derechos Humanos (OACDH) — cf. bibliografía - se ofrecen herramientas para combatir la discriminación contra indígenas, migrantes, minorías, discapacitados, mujeres, razas, religiones y determinadas orientaciones sexuales e identidades de género. Se omite incluso la posición económica, no digamos ya la condición de desempleado. Esto ofrece indicios de que puede merecer la pena confrontar esta
} 
se admite, en el peor de los casos, dicha relación, entonces se vuelve un recurso claro el apelar a ciertas teorías pragmáticas que dan cuenta del fenómeno comunicativo sirviéndose de algún tipo de explicación del proceso inferencial presente en la comunicación, pues consiguen dar mejor cuenta de esta característica: pensamos especialmente en casos en los que no se incluye ninguna entrada léxica especialmente ofensiva dentro del código empleado en el mensaje, pero que, al mismo tiempo, consiguen cumplir con las condiciones dadas para un discurso de odio en tanto que el emisor confía en la capacidad inferencial del receptor para interpretar la referencia subrepticia a estereotipos injuriosos para ese colectivo. La única desventaja clara de este enfoque, empero, es que normalmente su ámbito de actuación se reduce al enunciado, y no al discurso. Fijarnos en estas teorías pragmáticas inferenciales, siempre que recojan convenientemente los logros de la teoría de actos de habla, nos ayudará a dar cuenta de fenómenos pragmáticos que inciden especialmente en el caso de los discursos de odio dirigidos a este colectivo de los desempleados.

Sobre el asunto de la terminología, no se va a entrar especialmente a delimitar conceptual qué es "discurso de odio" o si, como se sugiere desde la organización, es preferible utilizar "discurso intimidatorio". Lo único que se mencionará, pues esto excede el alcance de este artículo, es que, como sostiene Goldberg (1995), la expresión "discurso de odio" psicologiza el fenómeno, categorizándolo dentro de un ámbito emocional que, en exceso, podría constituir un desorden. No obstante, con este énfasis es sencillo olvidar la dimensión normativa de esa manifestación discursiva, a saber: el pronunciamiento sobre lo correcto o incorrecto - desde un enfoque objetivo, añadiríamos - de dicho discurso.

Pero procédase ordenadamente. En primer lugar, la condición de posibilidad de esta intervención es constatar que, efectivamente, se producen discursos de odio contra este colectivo. Dividimos en tres ámbitos los discursos en los que puede rastrearse manifestaciones discursivas que atentan contra la dignidad del colectivo de los desempleados, cumpliéndose aquí aquella condición que John Stuart Mill imponía a la libertad de expresión en On Liberty: "prevenir el daño a otros" (MILL, 1978, p. 9). De ellos, se presentará algún ejemplo ilustrativo.

hipótesis, puesto cuenta con cierta plausibilidad. No obstante, esta tarea es algo que excede las pretensiones de esta investigación. 


\subsection{Manifestaciones discriminatorias, que incurren en intimidación, apelando a estereotipos degradantes que suponen prejuicios infundados contra ese colectivo}

Ciertamente no son pocos los ejemplos en los que existen manifestaciones, con intenciones injuriosas, dirigidas o bien al conjunto del colectivo de los desempleados o bien a algún individuo específico que es atacado en foros y redes sociales sirviéndose de estereotipos asociados a la figura del desempleado. Son especialmente frecuentes las calificaciones con connotaciones peyorativas, reflejadas en el código lingüístico con adjetivos calificativos tales como "vago" o "sponger" (gorrón) en inglés o el empleo de léxico con un fuerte componente connotativo tales como el uso de "paguita", en espańol, para referirse al subsidio de desempleo u otras prestaciones. Sobre esto, podemos encontrar cuantiosas entradas de hilos en muchos de los principales foros de Internet destinados a tratar, de forma exclusiva o complementaria, problemas políticos o sociales. Así, por ejemplo, en sitios web incluidos dentro de los 300 más visitados en España de acuerdo a los datos manejados por Alexa.com, tales como forocoches. com y burbuja.info, no es inusual encontrar entradas tales como "Hay que quitar la prestación a los vagos de los parados", "Ciudadanos excluye a los vagos de las paguitas", "No voy a contratar ni loco a un parado, no son de fiar", etc. Véase cómo aquí el ataque es impersonal, al colectivo en general, pero se plasma también en descalificaciones directas a usuarios de las redes que padecen esta situación. Así, por ejemplo, en elotrolado. net, popular entre los jóvenes, el usuario $n k o$ se dirige en estos términos a otro que expone sus dificultades para encontrar empleo: "Eres un vago y la hostia que te vas a dar es de órdago. Ponte las pilas o acabarás debajo de un puente" ${ }^{\prime \prime}$. No es necesario tampoco incidir en la multitud de ejemplos que pueden hallarse siguiendo esta línea, lo cual muestra claramente que no es un fenómeno aislado, sino que recurre sistemáticamente a un criterio grupal para proceder al comentario. Ni siquiera tampoco es necesario insistir más en este punto, que es probablemente el más fácilmente aprehensible

\footnotetext{
${ }^{5}$ http://asturiex.com/foros/foro-general/hay-que-quitar-la-prestacion-a-los-vagos-de-losparados-t6585-30.html [Consultado el día 7 de julio de 2017].

${ }^{6}$ https://www.forocoches.com/foro/showthread.php?t=4184972 [Consultado el día 7 de julio de 2017].

${ }^{7}$ http://www.elconfidencial.com/alma-corazon-vida/2012-10-22/ano-voy-a-contratar-ni-locoa-un-parado-no-son-de-fiara_401358/ [Consultado el día 7 de julio de 2017].

${ }^{8}$ https://www.elotrolado.net/hilo_el-hilo-de-los-parados-desempleados_2176232_s90

[Consultado el día 7 de julio de 2017].
} 
en primera instancia. No obstante, nos sitúan ya en posición para captar una propiedad en el terreno de lo denotativo común en todas estas manifestaciones discursivas propias de discursos de odio al desempleado: reduciendo la extraordinaria complejidad económica, cultural y sociológica de la situación de desempleo en las sociedades occidentales y, especialmente, en los países del sur de Europa - diseccionadas por varios autores, con independencia de su tamiz ideológico, por ejemplo Krugman (1994)_, el discurso de odio hacia el desempleo elimina visceralmente esa complejidad incidiendo en un solo factor: la denominación, con fuerte carga connotativa peyorativa, de "vago", como término que cuenta con la misma extensión que el término "desempleado", lo que incide en la visión ideológica, nunca confirmada empíricamente, de la atribución exclusiva de responsabilidad de la situación de desempleo en el individuo que padece tal situación; por otra parte, la denominación de "paguita" para nombrar al subsidio de desempleo se vale de las enormes y variadas connotaciones del sufijo -ito en español, rememorando con ella una denominación que las clases populares normalmente emplean para dotarla de un contenido connotativo extra que, al rememorar las características propias de dichas clases populares, consigue hacer recuperar en el receptor del mensaje todos los estereotipos vertidos sobre esas clases en la ideología neoliberal.

\subsection{Directrices de búsqueda y orientación de empleo en páginas web, documentos de sindicatos y servicios públicos de orientación}

En principio, parece un contrasentido que instituciones públicas, comúnmente sometidas conscientemente a los dictámenes de manuales de estilo, caigan en algún tipo de discurso de odio al desempleado, pero lo cierto es que, en no pocos casos, encontramos en los discursos dirigidos a este colectivo una serie de recomendaciones que, igualmente, inciden en unos supuestos de partida utilizados en la comunicación - $\mathrm{O}$ unas condiciones preparatorias en terminología de Searle (1969) - que presuponen la carencia completa de las condiciones requeridas para la obtención de empleo por parte del colectivo de desempleados al que va dirigido. Fijémonos, a modo de ejemplo, puesto que es algo extensible a otras guías tanto públicas como privadas, en la "Guía práctica para la búsqueda de empleo" actualmente empleada por el Servicio Andaluz de Empleo (SAE), dependiente de la Consejería de Empleo, Empresa y Comercio de la Junta de Andalucía. Dicho documento, en primer lugar, tiene como destinatario principal al desempleado, el cual es el receptor exclusivo de los consejos 
que en dicha guía se elaboran. Si bien, qué duda cabe, se recogen algunas orientaciones aparentemente bienintencionadas de cara al desempleado, tales como "conocerse a uno mismo" (SAE 2017, p. 3-4), "conocer el mercado laboral" (SAE 2017, p. 5-6), "cómo ofrecerte a una empresa" (SAE 2017, p. 14-15), lo cierto es que, en tanto que ejecutan el acto de habla de "aconsejar", presuponen la validez en las circunstancias actuales de la condición preparatoria que Searle (1969. p. 75) reserva para tal acto de habla, a saber: que no es obvio ni para el hablante ni para el oyente que el oyente hará el acto futuro $A$ en el curso normal de los acontecimientos. Dicha condición preparatoria supone, pues, que el organismo emisor de dicho documento considera necesaria la realización de tal acto de habla (de discurso) pues presupone, como condición preparatoria, que el desempleado no va a realizar en el curso normal de los acontecimientos actos de sentido común tales como preocuparse de reconocer qué requisitos demanda un puesto de trabajo o elaborar un plan de búsqueda con actividades tales como ampliar la formación o elaborar un curriculum vitae. Esto supone introducir al colectivo de desempleados, protagonizado en buena medida por jóvenes sobrecualificados, al menos en el caso español y de muchas sociedades occidentales, en estereotipos del desempleado denigrantes, achacándoles falta de aptitud para la consecución de un empleo, rasgo discutible en décadas pasadas donde el nivel de formación era menor, pero absolutamente inaceptable en el panorama actual. Conlleva, por tanto, agravar las implicaciones psicológicas y sociológicas en el desempleado, añadiéndole la rémora de las consecuencias derivadas de la amenaza del estereotipo, ampliamente estudiadas de forma empírica en el caso de otro tipo de estereotipos y admitidas, aunque sea de forma marginal, incluso por críticos (FLORE; WICHERTS, 2014). Por otro lado, una guía práctica para la búsqueda de empleo que no tiene contrapartida para la parte del empresario supone incidir nuevamente en un discurso de adjudicación de la responsabilidad de un problema de raigambre claramente social al individuo que padece esa situación.

Así pues, si bien claro está que los documentos de orientación y búsqueda de empleo elaborados por sindicatos y organismos gubernamentales no incurren en discursos de odio, sí son partícipes de propagar estereotipos denigrantes de la figura del desempleado que después son aprovechados por la opinión pública para incurrir en tales discursos. 


\subsection{Declaraciones y programas políticos}

El abuso -más que simple desacierto- en la ejecución del acto de habla en 3.2 se puede extrapolar también al contenido de determinados programas políticos, así como las manifestaciones discriminatorias recogidas en el punto 3.1 pueden verse reflejadas también en declaraciones ante los medios o expresiones espontáneas de políticos que, incluso, ejercen su labor como congresistas o senadores. Valga como ejemplo la proferencia de Fabra desde la bancada del Congreso, con su " $\mathrm{Q}$ ue se jodan!"”, dirigido a los parados españoles. Una vez más, incluso en esta expresión malsonante vuelve, en su aspecto designativo, a incidir en la atribución de la responsabilidad de una situación coyuntural de la sociedad española a aquellos que tienen la desdicha de sufrirla. Igualmente, con el asunto de las subvenciones, hay variados ejemplos en la política internacional, especialmente en sociedades donde el neoliberalismo caló con mayor hondura. Así, en Reino Unido encontramos ataques similares de los tories hacia los desempleados, cuando el ex-primer ministro británico David Cameron recogía en unas declaraciones a la prensa, tal como se recoge en el periódico The Guardian del 17/2/2015, que los desempleados jóvenes tendrían que hacer servicios a la comunidad bajo su mandato ${ }^{10}$ y que, de acuerdo al escritor y analista político John Wight (Huffpost Politics, 14/1/2013) constituye claramente un discurso de odio $^{11}$. En el ámbito nacional, Esperanza Aguirre comparó la prestación por desempleo con "una beca para disfrutar de un año sabático" (Expansión, $22 / 5 / 2015)^{12}$. Todas ellas son expresiones que sirven para afianzar prejuicios denigrantes contra esos colectivos, en un intento directo por humillarlos.

\section{Indagación al respecto de qué enfoque teórico permite explicar más satisfactoriamente las mencionadas manifestaciones discursivas}

Surge la cuestión sobre hasta qué punto este tipo de declaraciones constituyen expresiones verbales de odio y, si así lo fueran, qué tipo de

\footnotetext{
${ }^{9}$ http://www.lavanguardia.com/politica/20120713/54324975022/andrea-fabra-que-se-jodan. html [Consultado el día 7 de julio de 2017].

${ }^{10}$ https://www.theguardian.com/politics/2015/feb/17/unemployed-will-have-to-docommunity-work-under-tories-says-cameron [Consultado el día 7 de julio de 2017].

${ }^{11} \mathrm{http} / / / \mathrm{www} \cdot$ huffingtonpost.co.uk/john-wight/tory-attacks-on-the-unemployed_b_2455655.html [Consultado el día 7 de julio de 2017].

${ }^{12}$ http://www.expansion.com/economia/politica/2015/05/22/555f09a222601dab5d8b457a. html [Consultado el día 7 de julio de 2017].
} 
contribución especializada puede aportarse más allá de la constatación del fenómeno - paso este, de la descripción a la explicación, menos transitado en lingüística de lo que sería deseable-. Quisiera incidir, antes que nada, en que se está abordando la cuestión desde una óptica pragmática, lo que fuerza a centrarse sobre todo en el nivel del enunciado. Igualmente, estas reflexiones probablemente, pueden extrapolarse a discursos intimidatorios centrados en otras esferas de la realidad social.

\subsection{Evaluación de las teorías de la cortesía verbal}

En la pragmática, es común referirse a las diversas teorías de la cortesía verbal — tales como los de Leech (1983) o, en menor medida, Brown y Levinson (1987), por citar los clásicos - para dar cuenta de actos de (des) cortesía, implementando, por ejemplo, a través de Leech (1983) una explicación a partir de la violación de ciertas máximas y categorizándola como un caso en el que la intervención verbal se opone frontalmente al mantenimiento de la relación entre los interlocutores (y esta vía lleva a analizar enunciados como "La prestación por desempleo es una beca para disfrutar de un año sabático" como un enunciado que no solo burla la máxima de calidad griceana, sino también las máximas de tacto, de aprobación y de simpatía, cuando menos). Este análisis podría verse completado mediantes obras más actuales que probablemente sean más prometedoras, como la de Culpeper (2011, p. 155) cuando aborda la descortesía a través de las implicaturas. No obstante, este enfoque, si bien puede contar con cierto interés como primera aproximación, adolece de ciertos defectos graves, siendo el principal uno de carácter conceptual: no parece que propiamente el discurso de odio se centre en ser descortés, sino más bien en algo más insidioso, como es el ánimo de humillar a un colectivo marginado. Obviamente, la humillación puede ser un efecto de la descortesía, pero no necesariamente, por lo que, a mi juicio, seguir por esta línea nos conduce a identificar un objeto de estudio más genérico que el que propiamente constituyen los discursos de odio (intimidatorios, si se prefiere mejor este término).

\subsection{Evaluación de las teorías de actos de habla}

Otro camino claro, bastante frecuente y contemplado en algunas de las participaciones de este coloquio, es que, dado que se acaba de afirmar que la descortesía genera como efecto la humillación, esa búsqueda de efectos 
encaja más con la teoría de actos de habla estándar - y por teoría de actos de habla estándar se entiende la obra de Searle (1969)—. La descortesía en este caso se encaja dentro de la naturaleza propia de algunos actos ilocutivos (como afirmar, declarar, sentenciar, etc. algo cuyo contenido proposicional rememore algún estereotipo peyorativo o sentenciar algún prejuicio, entre otras opciones) que tendrían, como consecuencia frecuente, aunque no convencional, efectos perlocutivos tales como insultar, humillar, injuriar, etc. Puede decirse que hay varios problemas con este enfoque, aunque nos centraremos especialmente en dos:

1) En primer lugar, una desventaja muy evidente es que el enfoque sería mucho más útil si pudiese colocarse a los efectos perlocutivos como ilocutivos. Recordemos que, al menos en la primera versión austiniana, posteriormente traicionada, como defiende Sbisà (2004), por Strawson y Searle, los actos ilocutivos provocan efectos convencionales, pero los perlocutivos no (1975, p. 94-107). Sería más útil porque, si los efectos provocados por los enunciados intimidatorios fueran convencionales, podrían ser estudiados antes de ser enunciados, es decir, habría una evaluación previa de los efectos que provocan. En cambio, al no ser convencionales, los efectos son siempre evaluables solo en cada caso, lo que impide establecer una ley general de los efectos (humillantes, insultantes, injuriantes, etc.) que un acto ilocutivo puede generar. Esto es lo mismo que decir que enunciados como "No voy a contratar ni loco a un parado, no son de fiar" constituyen un acto ilocutivo tal como afirmar o prometer — recordemos que la locución, o el contenido proposicional en Searle (1969), no determina sin performativo explícito, e incluso con él, qué acto de habla se ejecuta concretamenteque, subsidiariamente, provoca un efecto no convencional de humillación, denigración, ofensa, etc. en el otro. Ante esta vía, autores como Butler supieron ver este punto. Butler (1997) critica la incongruencia, propia probablemente de un escaso conocimiento de la teoría de actos de habla, por la que teóricos como Langton o MacKinnon han intentado dar cuenta de discursos de odio (racistas, pornográficos, etc.) a través de la noción de ilocución (cf. 1997, p. 9-18) - aunque probablemente Butler le confiera a este hecho otro sentido. Fijémonos cómo el propio Austin parecería estar claramente a favor de esta perspectiva de incluir los efectos de los discursos de odio como actos perlocutivos, pues él mismo advierte del ridículo que supone intentar insultar a alguien a partir de la cláusula "Te insulto", como pasa con actos ilocutivos como prometer, afirmar, felicitar, etc. (aunque, eso sí, refiriéndose no al acto perlocutivo sino a los performativos, cf. 1975, p. 25-38). 
En resumen, abordar los discursos de odio dentro de la dimensión perlocutiva aleja a estos de cualquier tratamiento lingüístico y, en último término, de cualquier ámbito que pueda constituir una ciencia seria, dada la impredictibilidad del resultado del acto ilocutivo en contexto. Es por ello que Austin concedía tanta importancia a la posibilidad de los desaciertos y los abusos, lo que abre la galería de las posibles formas en las que un enunciado como "Eres un vago y la hostia que te vas a dar es de órdago" u otros no consiga, después de todo, un efecto perlocutivo en el que se provoque daño al otro.

2) Una segunda razón clara, en la que no nos vamos a extender demasiado, es que la teoría de actos de habla no es autónoma en su explicación de los intercambios comunicativos, siendo dependiente de su integración en algún tipo de teoría pragmática inferencial para dar cuenta de los frecuentes actos de habla indirectos que se dan en la práctica — esto es algo de lo que ya se percató Searle (1969), integrando el análisis de los actos de habla indirectos en un proceso inferencial inspirado en modelo griceano-. Por tanto, un análisis exclusivo en actos de habla está condenado a no poder dar cuenta por completo de los problemas puramente lingüísticos que surgen a la hora de explicar la idiosincrasia propia de un enunciado intimidatorio.

\subsection{Evaluación de teorías inferenciales (teoría de la relevancia) y rehabilitación parcial de la teoría de actos de habla para los discursos objetivos de odio}

Fíjense cómo este punto 2 no conlleva necesariamente a aceptar la visión opuesta, a saber: que una teoría inferencial fuera autosuficiente para explicar cómo suceden y se interpretan comunicativamente los enunciados intimidatorios. Ello porque, en primer lugar, supondría restringirse sustancialmente a una perspectiva estrictamente comunicativa de la cuestión, cuando es obvio que la repercusión del discurso de odio va mucho más allá de limitarse a un ámbito comunicativo o lingüístico — sus repercusiones, como se han visto en este coloquio, son también éticas, jurídicas, sociales, etc.- . En segundo lugar, existen razones técnicas dentro de este tipo de teorías que impiden que, por sí solas, expliquen esta problemática. Tómese como ejemplo la teoría de la relevancia y aventúrese de qué forma podría explicarse el efecto producido por un enunciado intimidatorio. Lo primero que habría que mantener, como defiende Lewis (2014) respecto a las aproximaciones a través de semántica de condiciones de verdad, es que la teoría de la relevancia no tendría, por sí sola, herramientas conceptuales 
para tratar a los discursos de odio (o a los enunciados intimidatorios) de forma diferente a como trataría cualquier otro enunciado. Siendo esto así, un enunciado intimidatorio actuaría siendo relevante en aquellos casos en los que consiga efectos contextuales que modifiquen el entorno cognitivo mutuo de acuerdo a los cuatro casos que prevén Sperber y Wilson (cf. 1995, p. 143$)^{13}$. No obstante, el problema reside no solo en la evidente desventaja de no conseguir atribuir ningún tipo de especificidad a un discurso como el de odio que tiene consecuencias sociales, políticas, éticas, etc. mucho más perjudiciales. También desde un punto de vista teórico puede defenderse que, al ser la teoría de la relevancia una teoría centrada básicamente en cómo un oyente interpreta un enunciado, sería precisamente el oyente quien determinaría de qué forma el enunciado del hablante tiene ciertos efectos contextuales que modifiquen el entorno cognitivo mutuo. Ello implicaría no solo que podrían darse casos de malentendidos en los que un enunciado intimidatorio o de odio podría no ser captado como tal por el oyente debido a las escasas habilidades del comunicador o del oyente, o a su falta de conocimiento enciclopédico para recuperar un supuesto relativo a prejuicios de clase, por ejemplo — tal como se prevé en la revisión en la segunda edición de la presunción de relevancia óptima revisada (SPERBER; WILSON 1995, p. 270)—, lo que no obstaría para que fuera, a pesar de todo, un enunciado intimidatorio considerado desde un enfoque objetivo. En resumen, un defecto que ya no solo se aplica a los discursos de odio, sino a cualquier enunciado en general, es que la teoría de la relevancia es una teoría centrada en explicar cómo interpreta un receptor ciertos estímulos ostensivos, no es una teoría sobre cómo deben interpretarse estos estímulos ostensivos o sobre qué significan objetivamente — sobre esto se habla más extensamente en Rosso (2016)—. Esto tiene una incidencia especial en los enunciados intimidatorios hacia los desempleados, por una razón que explicaremos en la parte final.

Como consecuencia, consideramos que la teoría de actos de habla, especialmente con sus actuales desarrollos, sí tiene un papel que desempeñar en el análisis de los discursos de odio, aunque tenga luego que ser integrada en algún tipo de teoría pragmática inferencial (como la (neo)griceana o la

\footnotetext{
${ }^{13}$ La recuperación de dicho supuesto supondrá una modificación del entorno cognitivo mutuo de hablante y oyente, tendrá por tanto efectos contextuales relevantes en tanto que se amolda siempre a uno de los cuatro casos en los que Sperber y Wilson (1995, p. 143) consideran relevante un supuesto: a) cuando se da un reforzamiento a través del nuevo supuesto de un supuesto contenido en contexto inicial y accesible pero no con fuerza máxima; b) cuando el supuesto nuevo no está contenido y tiene implicaciones contextuales respecto al contexto inicial; c) cuando el supuesto nuevo no está contenido en el contexto inicial pero sí en tiene efectos en algún contexto accesible; d) cuando el supuesto nuevo no está contenido en el contexto inicial, pero sí máximamente en los accesibles, supone un recordatorio.
} 
relevantista). Precisamente, la teoría de actos de habla es la que consigue corregir y precisar, probablemente mejor que ninguna otra teoría, una de las condiciones que según Kaufman (2015, p. 151-152), autor que ha ganado relevancia en el ámbito latinoamericano, define a los discursos de odio: el criterio de intencionalidad — que lo enuncia como "intención deliberada de humillar o excluir a personas discriminadas"- Concretamente, los avances en la teoría de actos de habla permite discernir mejor cómo esa intención deliberada no es una condición necesaria para que se dé un discurso de odio, al poderse reconocer tanto que un enunciado resulte intimidatorio sin intención deliberada de humillación, como que resulte no intimidatorio a pesar de que se realice con la mencionada intención deliberada de humillar a un colectivo (el de los desempleados, en nuestro caso).

\section{La noción de contexto objetivo en el tratamiento conceptual de los discursos de odio}

El fenómeno que se está abordando es aquel en que un enunciado causa una humillación, siendo esa humillación basada no en rasgos individuales, sino en rasgos propios de un colectivo marginado. Este fenómeno es especialmente pertinente en el caso del colectivo de los desempleados porque, al no ser un colectivo que cuente con una visibilidad social específica como colectivo, no despierta tan claramente los reparos de lo políticamente correcto como suele suceder en cuestiones de género o raza. Se enuncian mensajes cuyo contenido proposicional presupone sistemáticamente la carencia o la insuficiencia de las habilidades profesionales o académicas necesarias para obtener un empleo (o montar un negocio), Póngase como ejemplo el tratamiento que la mencionada "Guía práctica para la búsqueda de empleo" reserva hacia la elaboración de un curriculum vitae, con enunciados como "Normalmente el CV debe aportar los datos personales" (p. 10). Claramente, la intención del emisor no es humillar a ese colectivo, pero en la medida en la que presupone ciertas condiciones preparatorias que no se dan en muchos miembros de dicho colectivo, el enunciado se vuelve, cuando menos, inadecuado y, en nuestra interpretación, humillante objetivamente. En casos más claros, como el mencionado "Ponte las pilas o acabarás debajo de un puente", no tiene por qué existir necesariamente una intención humillante hacia el receptor del mensaje en tanto que desempleado, pero constituye una referencia a una serie de propiedades estereotípicas y falaces del desempleado que menoscaban su autoestima y dignidad personal, independientemente de si el receptor interpreta o 
no de esa forma el enunciado. Precisamente para estos casos, el trabajo de la filósofa del lenguaje italiana, Marina Sbisà, aporta las herramientas conceptuales necesarias para captar la distinción. Ella proclama, en trabajos como su artículo "Speech Acts in Context" (2002), que un enunciado como "Discúlpame por haber roto tu jarrón" sería una disculpa exitosa si hablante y oyente compartieran como supuesto que el hablante fue el culpable de haber roto el jarrón pero que, desde un contexto objetivo, tendría que considerarse un acto de habla no logrado si realmente el emisor no fuese el culpable de dicha rotura del jarrón —es parecido, pero no igual, a lo que Austin llama actos insinceros, cuentan como realización, pero hay un abuso en el procedimiento-. Pues bien, este mismo enfoque, el del reconocimiento de la existencia de un contexto objetivo, es especialmente aprovechable en el caso de los enunciados intimidatorios hacia los desempleados: puesto que no hay, aún, un reconocimiento social del problema equivalente a la discriminación hacia otros colectivos, se está dando una serie de enunciados y discursos de odio que pasan subjetivamente desapercibidos. Solo los casos más claros, conteniendo insultos, epítetos, etc., es decir, aquellos casos registrables desde el código lingüístico, sin depender especialmente de la intención, son los que actualmente tienen visos de ser reconocidos, al menos ateniéndonos al discurso de odio hacia el desempleado.

El contexto objetivo supone, por tanto, una vía para tratar aspectos normativos relativos a la ilocución, es decir, introduce la capacidad de reconocer un enunciado intimidatorio sin depender ni de la intención del hablante, que puede ofender sin ni siquiera ser consciente, ni de la capacidad de interpretación del oyente, que puede ser ofendido sin ni siquiera haber creado la conciencia crítica necesaria para percatarse de ello.

\section{Conclusiones}

Habiéndose expuesto una serie de ideas directrices de una línea de investigación en curso, obtenemos las siguientes conclusiones, que son, a su vez, una invitación a continuar su desarrollo:

1. El colectivo de los desempleados no se identifica especialmente como un colectivo marginado. La elaboración de una genealogía crítica rastrea y denuncia tal situación. Hace visible su especial vulnerabilidad en un contexto de desaparición progresiva del valor del trabajo como principal agente vertebrador de la vida social. 
2. Existen manifestaciones discursivas evidentes y otras no tan evidentes de enunciados intimidatorios para desempleados. Se relatan justificadamente algunos lugares donde puede rastrearse su aparición.

3. En una reflexión general, se ha convenido en que ni las teorías de la cortesía, ni diversas teorías inferenciales como la de la relevancia ni la teoría de los actos de habla por sí solas sirven para dar cuenta de esos enunciados intimidatorios si se atiende no solo a su aspecto performativo, sino a su dimensión comunicativa, apostándose por una teoría de actos de habla integrada en alguna inferencial.

4. La falta de visibilización del desempleado lleva al empleo de recursos conceptuales como la noción de contexto objetivo de Sbisà, lo cual pensamos que puede ser una prometedora línea de investigación.

\section{Referencias}

AGAMBEN, Giorgio. Profanaciones. Traducción de Flavia Costa y Edgardo. 1. ed. Buenos Aires: Adriana Hidalgo Ed., 2005.

AHMED, Sara. The Cultural Politics of Emotion. Edinburgh: Edinburgh University Press and Routledge, 2004.

AUSTIN, John Langshaw. How to Do Things with Words. Oxford: Clarendon Press, 1975.

BAZZICALUPO, Laura. Biopolítica: un mapa conceptual. S/C Tenerife : Melusina, 2016.

BENJAMIN, Walter. El capitalismo como religión. Traducción de Omar Rosas. 2008. Disponible en: <http://fundp.academia.edu/OmarVRosas/ Papers/538833/El_capitalismo_como_religion_Walter_Benjamin $>$. Acceso en: 7 jul. 2017.

BLACK, Bob. La abolición del trabajo. Traducción de Federico Corriente 2. ed. Logrońo: Pepitas de Calabaza, 2013.

BOLTANSKI, Luc; CHIAPELLO, Éve. El nuevo espíritu del capitalismo. Madrid: Akal, 2002.

BROWN, P.; LEVINSON S. Politeness: Some universals in language usage. Cambridge: CUP, 1987.

BUTLER, Judith. Excitable Speech. A Politics of the Performative. New York/London: Routledge, 1997. 
CULPEPER, Jonathan. Impoliteness: Using Language to Cause Offence. Cambridge: CUP, 2011.

FERREIRO, Jesús et al. Teoría Insider-Outsider y temporalidad en el mercado de trabajo espańol. Revista del Ministerio de Trabajo y Asuntos Sociales Economía y Sociología, n. 51. p. 31-54, 2004. Disponible en: <http://www.empleo.gob.es/es/publica/pub_electronicas/destacadas/ revista/numeros/51/Revista51.pdf>. Acceso en: 7 jul. 2017.

FLORE, P. C.; WICHERTS, J. M. Does stereotype threat influence performance of girls in stereotyped domains? A meta-analysis. Journal of School Psychology, n. 53, v. 1, p. 25-44, 2014.

FREUD, Sigmund. El Porvenir de una Ilusión. Buenos Aires: Amorrortu, 2016.

GARZA, Enrique de la. El trabajo del futuro: ¿̨Fin del trabajo o trabajo sin fin? 1999, p. 13-40. Disponible en: <http://sgpwe.izt.uam.mx/pages/egt/ congresos/ftotsf.pdf>. Acceso en: 7 jul. 2017.

GOLDBERG, David Theo. Afterword: Hate or Power? In: WHILLOCK, R. K.; SLAYDEN, D. (eds.). Hate Speech. Thousand Oaks: Sage, 1995. p. 267-276.

INE. Encuesta de Población Activa (EPA), 2012-2016, Disponible en: <http://www.ine.es/prensa/epa_tabla.htm>. Acceso en: 7 jul. 2017.

KAUFMAN, Gustavo A. Odium dicta Libertad de expresión y protección de grupos discriminados en internet. México, D. F.: Consejo Nacional para Prevenir la Discriminación, 2015. Disponible en:< http://www.conapred. org.mx/documentos_cedoc/OdiumDicta_WEB-INACCSS.pdf.>. Acceso en: 7 jul. 2017.

KRUGMAN, Paul. Past and prospective causes of high unemployment. Paul. Economic Review, Kansas City, Federal Reserve Bank of Kansas City 79, D4, 1994.

LACALLE, Daniel. Trabajadores precarios: trabajadores sin derechos. Barcelona: El viejo topo, 2009.

LAHIRE, Bernard et al. Lo que el trabajo esconde: materiales para un replanteamiento del análisis sobre el trabajo. Madrid: Traficantes de sueńos, 2005. 
LEECH, Geoffrey. Principles of Pragmatics. London: Longman, 1983.

LEWIS, Myles. 'You're Not Like Other' Hate Speech, 2014. Disponible en: <https://papers.ssrn.com/sol3/papers.cfm?abstract_id=2399644>. Acceso en: 7 julio 2017.

OFICINA DEL ALTO COMISIONADO PARA LOS DERECHOS HUMANOS. Speak Up Stop Discrimination. Disponible en: <http:// ohchr.org/EN/Issues/Discrimination/Pages/discrimination.aspx $>$. Fecha de consulta: 7 jul. 2017.

MORUNO, Jorge. La fábrica del emprendedor. Trabajo y política en la empresa-mundo. Madrid: Akal. 2013.

RAVENTÓS, Daniel. Propiedad, libertad republicana y Renta Básica de Ciudadanía. Polis, n. 10, 2005. Disponible en: <http://polis.revues. org/7503>. Acceso en: 7 jul. 2017.

RAZAVI, A. et al. Offensive language detection using multi-level classification. Advances in Artificial Intelligence, Springer, Berlin/ Heidelberg, 2010.

ROSSO CARRASCO, Miguel. Problemas epistemológicos asociados a la implementación de la ilocutividad en teorías pragmáticas naturalistas, 2016. Disponible en: <https://www. educacion.gob.es/teseo/imprimirFichaConsulta.o;jsessionid= D6A33F7172EAC9E66A31F3E7ECBDACDB?idFicha=404441>. Acceso en: 7 jul. 2017.

SARTRE, Jean-Paul. Crítica de la razón dialéctica. Buenos Aires: Losada, 2004.

SAVATER, Amador. Discutir la configuración neoliberal de lo humano (postal desde Nueva York). 2015. Disponible en: <http://www.eldiario.es/interferencias/neoliberalismo15M_6_122897713.html>. Acceso en: 7 jul. 2017.

SBISÀ, Marina. Speech Acts in Context. Language \& Communication, n. 22, p. 421-436.

SEARLE, John. Speech Acts. Cambridge: CUP, 1969.

SERVICIO ANDALUZ DE EMPLEO - SAE. Guía práctica de búsqueda de empleo. Disponible en 
<http://www.juntadeandalucia.es/export/drupaljda/Guia_Practica_ Busqueda_Empleo.pdf>. Acceso en: 7 jul. 2017.

SPERBER, D.; WILSON, D. Relevance: Communication and Cognition. Blackwell: Oxford, 1995.

TIQQUN. Tiqqun 1.Exercices deMétaphysique Critique. Los metafísicoscríticos desde el "movimiento de los parados". 1999. Disponible en: $<$ http://tiqqunim.blogspot.com.es/2013/12/los-metafisicos-criticos-bajoel.html>. Acceso en: 7 jul. 2017.

Daniel López Romero <lopez.romero.daniel@gmail.com> Miguel Rosso Carrasco <miguel.rosso@uca.es> Recebido: 31/07/2017 Aceito: 05/10/2017 